\title{
Utilization of rigid polyurethane foam waste in removal of uncontrolled releases of hazardous substances
}

\author{
Tomasz Węsierski ${ }^{1, *}$ \\ ${ }^{1}$ Szkoła Główna Służby Pożarniczej (Main School of Fire Service), Juliusza Słowackiego 52/54, \\ 01-629 Warsaw, Poland
}

\begin{abstract}
In 2017 in Poland 12522 incidents involving hazardous substances were recorded, of which 23 have been classified as large and very large. Apart from the share of carbon monoxide, most of them concerned uncontrolled petroleum product releases. In the same year over $427 \mathrm{~m}^{3}$ of foaming agents were used. Consequently, an extremely important issue at the intervention level is the efficient and safe removal of the resulting pollution. Tests of maximal absorption proprieties with the use of the modified Westinghouse method executed on a wide range of industrially used diverse industrial toxic substances and various classes of waste of firefighting foam agents have demonstrated substantial usability of rigid polyurethane foam waste. The obtained maximal theoretical sorptivity were within the range of $1.87-5.11 \mathrm{~kg} \mathrm{~kg}^{-1}$. It has also been proven that absorption proprieties in relation to waste firefighting foaming agents were reduced. However, the maximum absorption proprieties of the tested rigid polyurethane foam waste are much higher than those for standard mineral sorbents used in rescue operations, which indicates a high potential for their practical use for emergency services.
\end{abstract}

\section{Introduction}

Data of the Polish Headquarter of State Fire Service indicate that only in 2017 there were 12522 incidents involving uncontrolled releases of hazardous substances in Poland, of which 23 were large and very large scale [1].

Apart from the share of carbon monoxide, most of them concerned uncontrolled petroleum products releases. In the same year over $427 \mathrm{~m}^{3}$ foaming agents were used. A significant number of accidents involving dangerous substances make it necessary to search for new and more ecological solutions that enable the removal of environmental hazards generated during the incidents. An ever increasing attention is paid to problems related to post-incident waste of foaming agents. These agents, due to the surfactants contained in them, may have an adverse effect on the environment [2-10]. One of the solutions enabling an easy and safe removal of hazardous substances is the use of sorbents, which, depending on their bulk density, can be used both in land and water actions [11]. Their

\footnotetext{
* Corresponding author: wesierskitomas@ poczta.onet.pl
} 
non-reactivity to the absorbed substances, the ease and intuitive use, as well as the possibility of subsequent controlled utilization allows their use as a cheap and safe means of removal smaller quantities of dangerous substances on the spot. Given the characteristics of sorbents during actions carried out only by the State Fire Service in 2017 almost 797 tons were used.

\section{Research methodology}

Maximal theoretical sorptivity measurements were carried out using the modified Westinghouse method. The presented modification is an original research and interpretation concept. Water, water solutions of Fomtec AFFF 3\% S and BIO FOR C foam concentrate (conc. 0.1-3\%) and selected dangerous substances and their solutions used industrially were subjected to testing (Table 1). Pumice powder from PUMICE-I.M.P.A S.C being a waste of rigid polyurethane foam was used as sorbent. Before proceeding with the specific tests, the material was sieved to obtain a uniform powder with a grain size of $\varnothing \leq 1 \mathrm{~mm}$. The microscopic picture of rigid polyurethane foam waste used in research is shown in Figure 1.

Table 1. Substances and solutions used in experiments

\begin{tabular}{|c|c|}
\hline Measured substance and their content & Producer \\
\hline $\begin{array}{l}\text { 1-Propanol (99.5\%), Toluene (99.5\%), Benzyl alcohol (99.8\%), } \\
\text { Ethylene glycol (98.5\%), Cyclohexanol (99\%), 2-Butanol (99.5\%) }\end{array}$ & CHEMPUR \\
\hline $\begin{array}{c}\text { Glycerol }(99.5 \%), \text { n-Hexane }(995 \%), \text { Cyclohexane }(99.5 \%), \\
\text { Propylene glycol }(99.5 \%), \text { Methanol }(99.8 \%), 1-\text {-Butanol }(99.5 \%) \\
\text { 3-Methylbutan-1-ol }(99.5 \%), 1-\text {-Octanol }(99 \%) \text {, Acetone }(99.5 \%), \\
\text { 2.4-Dihydroxy-2-Methylpentane }(99 \%), 2,2-\text {-oxydiethanol }(99 \%), \\
\text { chloroform (99.5\%), Phosphoric acid (85\% water solution), } \\
\text { Ammonia (25\% water solution), sodium hydroxide (40\% water solution), } \\
\text { sulphuric acid (pure and 30\% water solution) }\end{array}$ & $\mathrm{POCH}$ \\
\hline $\begin{array}{c}\text { Acetic acid (99,5\%), 2-Ethoxyethanol (99\%), 1,4-Dioxane (99,8\%), } \\
\text { Cyclohexanone (99,5\%), 4-Nitrotoluene (98\%), Methyl acetate (98\%), } \\
\text { 2-Methyl-2-hydroxy-2-pentanone (99\%), Ethyl benzoate (98\%), } \\
\text { 2-Methoxy-2-methylbutane (min 97\%), Nitrobenzene (99\%) }\end{array}$ & $\begin{array}{l}\text { Sigma- } \\
\text { Aldrich }\end{array}$ \\
\hline 4-methyl-2-pentanone (98\%), 1-Decanol (98\%) & Fluka \\
\hline n-Octane $(99,5 \%)$ & Merck \\
\hline 1-Undecanol & SERVA \\
\hline Gasoline, Diesel oil & - \\
\hline $\begin{array}{l}\text { Formtec AFFF } 3 \% \mathrm{~S} \text { (solutions } 0,1 \%, 0,5 \%, 3 \% \text { ). } \\
\text { Fomtec AFFF } 3 \% \mathrm{~S} \text { - an aqueous film forming foam concentrate consisting of } \\
\text { fluorocarbon and hydrocarbon surfactants }\end{array}$ & FORMTEC \\
\hline $\begin{array}{l}\text { BIO FOR C (solutions } 0,1 \%, 0,5 \%, 3 \%) \\
\text { BIO FOR C - a synthetic class A foaming concentrate. }\end{array}$ & BIO-ex \\
\hline
\end{tabular}

10 grams $\left(\mathrm{m}_{\mathrm{o}}\right)$ of the previously sieved sorbent were placed in a conical stainless steel strainer with a diameter of $70 \mathrm{~cm}$ and a height of $7.5 \mathrm{~cm}$. The test sample prepared in this way was immersed in the sorbed liquid (sorbate). The sorbent was immersed in the sorbed liquid until it was completely wetted. Then the sample was pulled from the liquid and hung on the previously tared balance and the time measurement was started. During the measurement, the mass of rigid polyurethane foam together with sorbed liquid as a function of time for 40 minutes was recorded. The mass of sorbed liquid was calculated by subtracting the mass of the sieve and sorbent. Dividing this value by the sorbent mass, absorbency was obtained. On the basis of the obtained results, diagrams of temporary sorptivity as a function of residence time in the strainer were made. The value of the maximal theoretical sorptivity 
$\left(A_{\max }\right)$ of the sorbent relative to a given liquid was obtained by extrapolating the evaporation straight to the OY axis.

An evaporating straight is defined as a straight related to the mass loss of sorbed liquid from the sorbent space due to the evaporation process. Extrapolation to the OY axis allowed taking into account the loss of sorptivity resulting from the evaporation of the sorbed liquid from the sorbent space, whereby the maximal theoretical sorptivity (Amax) was obtained at time $t=0$. The method for determining $A_{\max }$ is shown in Figure 2 .

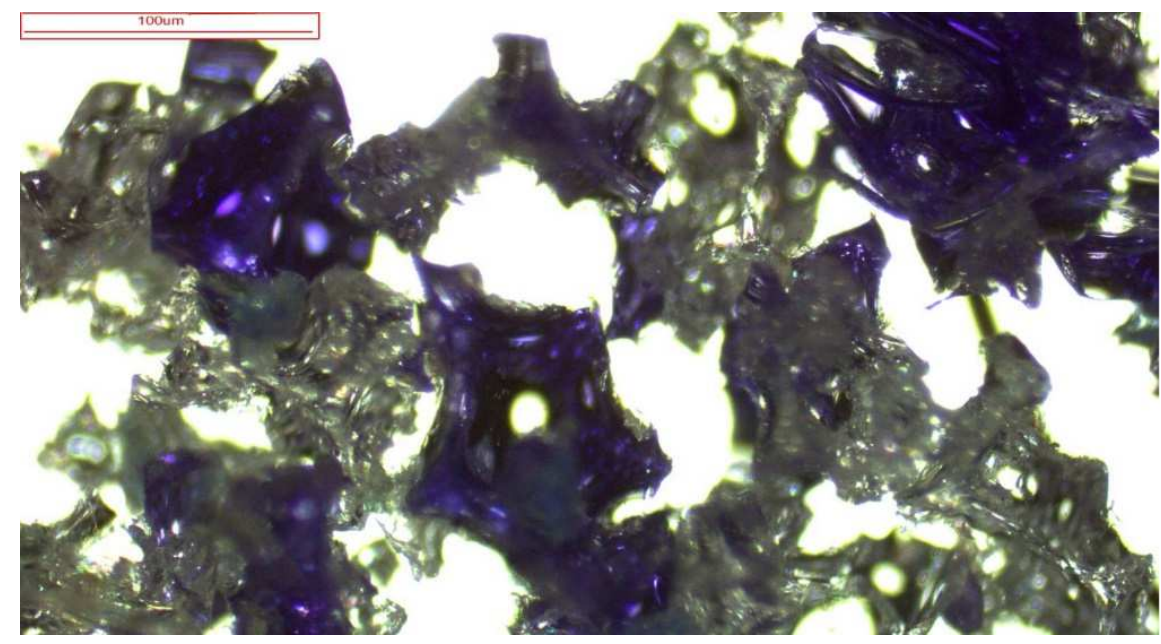

Fig. 1. Microscopic picture of rigid polyurethane foam used in investigations

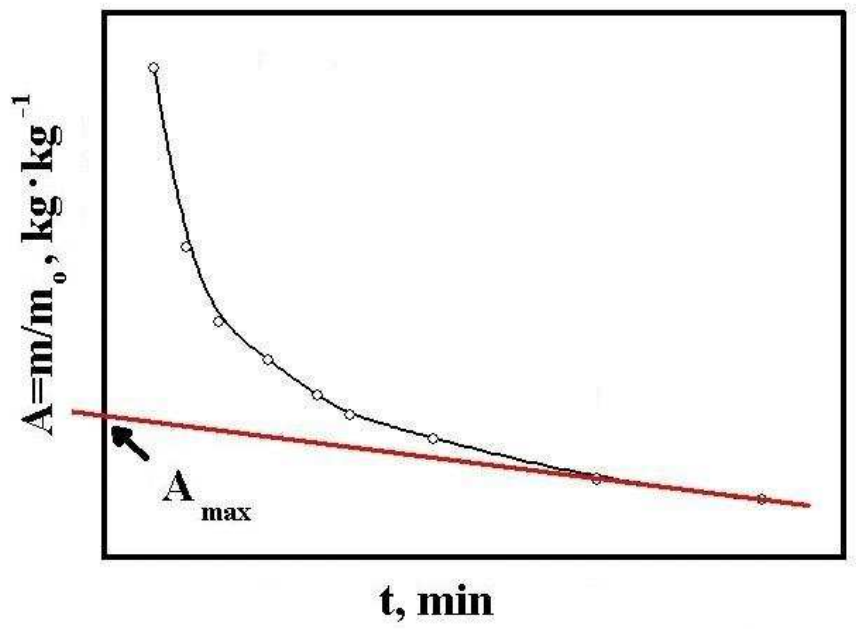

Fig. 2. Determination of the theoretical maximal sorptivity (Amax) obtained by extrapolation of evaporation straight line to the OY axis

In the initial stage of suspension in the strainer there is a leak and then dripping takes place of the sorbed liquid from the sorbent space. At a later stage, the dripping process ceases. Mass loss occurs as a result of evaporation of the sorbed liquid. The standard Westinghouse method in the calculation included only the sorbed mass of the sorbate after $40 \mathrm{~min}$. of dripping without taking into account measurement and sorbate mass analysis as a function of time. 


\section{Results and discussion}

Exemplary curves of dependence of temporary sorptivity as a function of residence time in sieve $A=f(t)$ for selected sorbates being hazardous substances are shown in Fig. 3. Fig. 4 shows curves $A=f(t)$ of selected solutions of foaming agents with different concentrations, and a comparison was then performed with the curve of water sorption. Extrapolation of the curve points associated with the evaporation stage to point $t=0$ allowed the determination of the maximal theoretical sorptivity of sorbent $A_{\max }$ in relation to the sorbate, taking into account the mass which has evaporated. The results obtained are summarized in Table 2 and 3. The plot of $A_{\max }$ versus density of sorbed liquids is presented in Fig. 5.
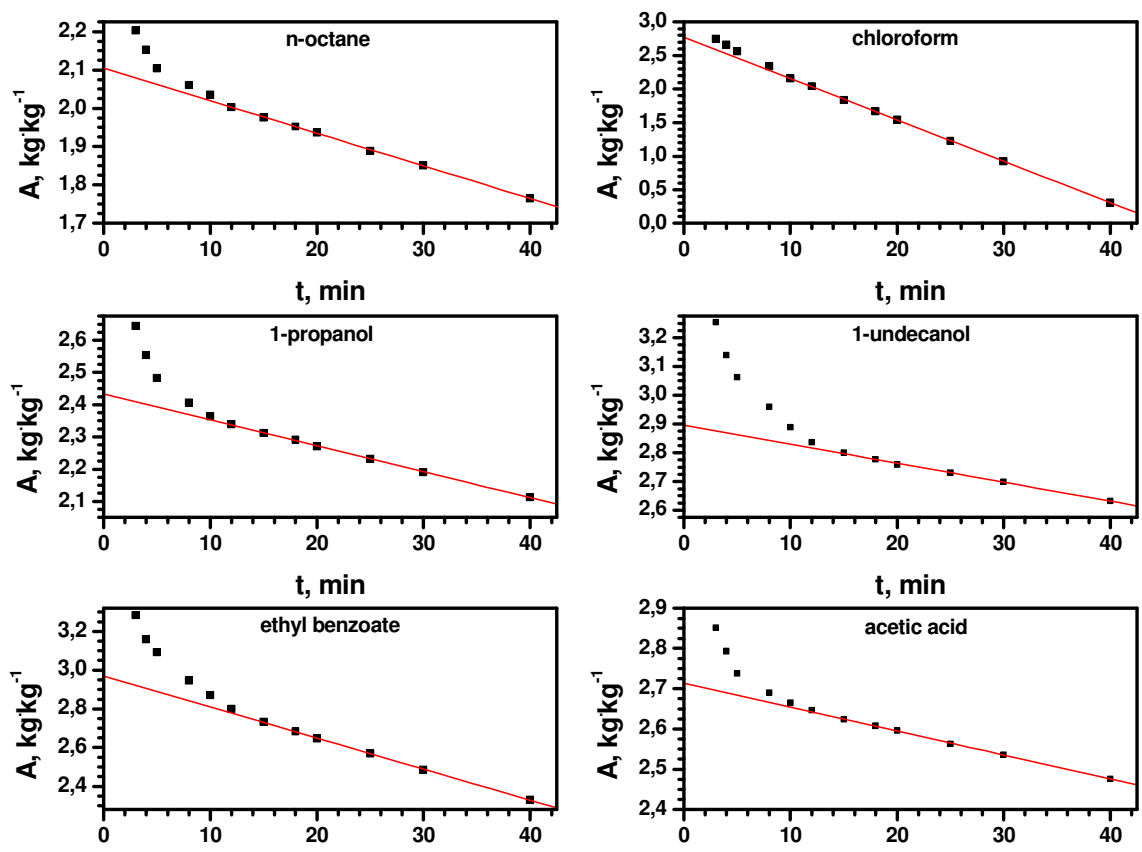

t, $\min$
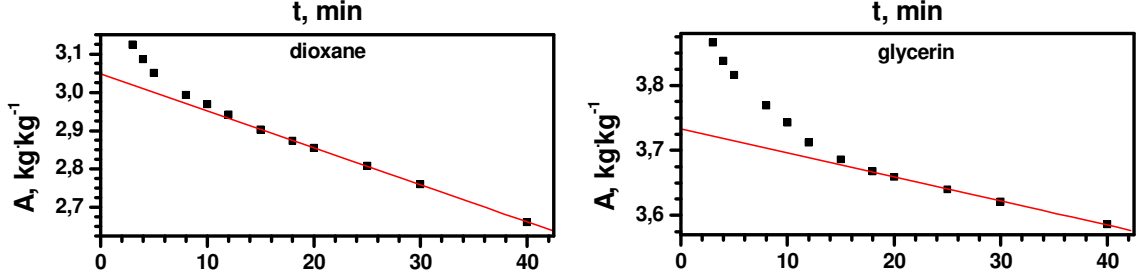

$t$, min
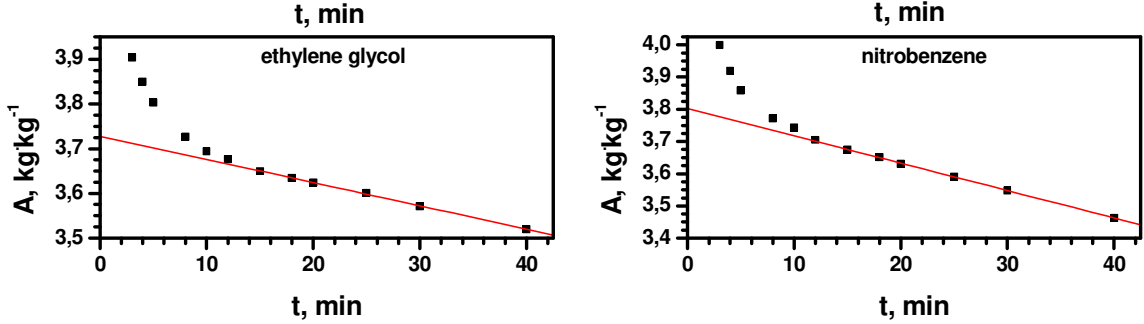

Fig. 3. Exemplary curves of dependence of temporary sorptivity as function of residence time in sieve $A=f(t)$ for selected sorbates. 
The obtained results indicate that the maximal theoretical sorptivity ranges from 1.87 to $5.11 \mathrm{~kg} \mathrm{~kg}^{-1}$, reaching the lowest value for $\mathrm{n}$-Hexane and gasoline and the highest one for $85 \%$ phosphoric acid solution. A linear relationship between Amax and the density of sorbed liquid was ascertained. This is due to the fact that the available sorption space of the sorbent is the same, and any differences that may be observed could arise from excessively high surface tension or excessively high density that hinders the maintenance of liquid in the open pores. A surface tension that is too low facilitates leakage of the substance, similarly as an excessive specific gravity. This can be found by analyzing the curves $A=f(t)$ for solutions of foam agents (Figure 4).
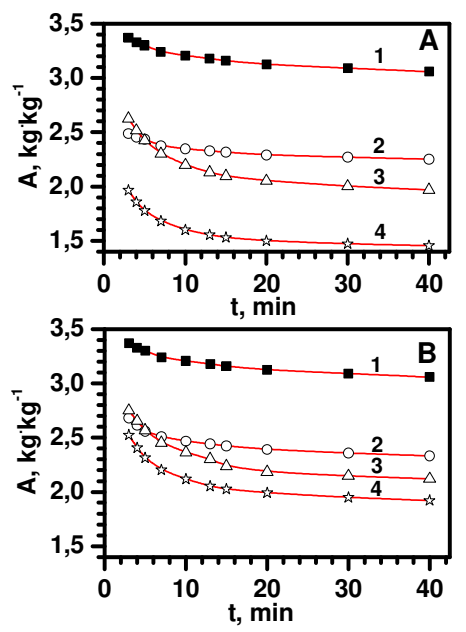

Fig. 4. Dependence of temporary sorptivity as a function of residence time in sieve $A=f(t)$ for water and selected foam agent solutions of different concentrations. Fig. A: 1) water; 2) 0.1\% Formtec AFFF 3\% S; 3) 0,5\% Formtec AFFF 3\% S; 4) 3\% Formtec AFFF 3\% S; Fig. B: 1) water; 2) $0.1 \%$ BIO FOR C; 3 ) $0,5 \%$ BIO FOR C; 4) $3 \%$ BIO FOR C.

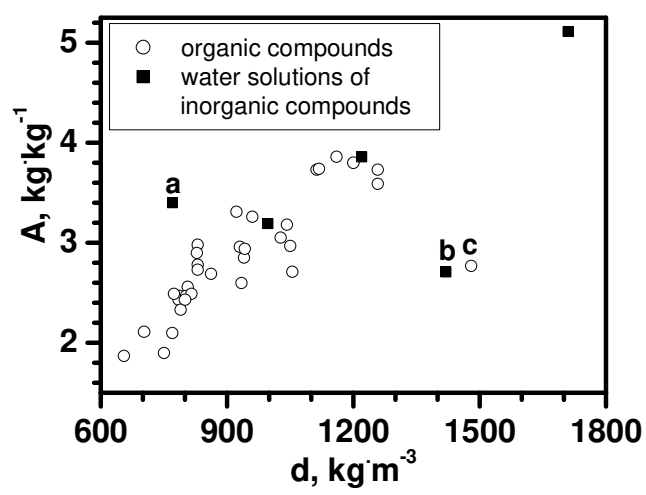

Fig. 5. Dependence of maximal theoretical sorptivity as a function of sorbate density with a breakdown into studied organic substances and aqueous solutions of inorganic substances and water. As points a, b and c are marked Amax of solutions that stand out from the trend line where: a) $25 \%$ ammonia water solution b) $40 \% \mathrm{NaOH}$ water solution c) chloroform.

Their presence causes a decrease in surface tension and as the concentration increases, the decrease of the sorptivity is observed. On the other hand, the effect of specific gravity 
may be responsible for low chloroform sorption. The capillary forces would be unable to support the weight of sorbed liquid, which may be clearly seen on the basis of the very low $\mathrm{A}_{\max }$ determined for this substance. Rigid polyurethane foam reaction with the investigated sorbates has not been ascertained except for concentrated $\mathrm{H}_{2} \mathrm{SO}_{4}$.

Table 2. Determined values of maximal theoretical sorptivity $A_{\max }$ and relative porosity AV.

\begin{tabular}{|c|c|c|c|}
\hline Substance & $\mathrm{d}, \mathrm{kg} \cdot \mathrm{m}^{-3}$ & $A_{\max }, \mathrm{kg} \cdot \mathrm{kg}^{-1}$ & Av, $\mathbf{m}^{3} \cdot \mathbf{m}^{-3}$ \\
\hline Metanol & 787 & 2,47 & 0,590 \\
\hline 1-Propanol & 785 & 2,43 & 0,582 \\
\hline 1-Butanol & 806 & 2,56 & 0,597 \\
\hline 2-Butanol & 802 & 2,47 & 0,579 \\
\hline 3-Methylbutan-1-ol & 815 & 2,49 & 0,574 \\
\hline Cyclohexanol & 960 & 3,26 & 0,638 \\
\hline 1-Octanol & 830 & 2,78 & 0,630 \\
\hline 1-Decanol & 830 & 2,98 & 0,675 \\
\hline 1-Undecanol & 828 & 2,90 & 0,658 \\
\hline 2-Ethoxyethanol & 930 & 2,96 & 0,598 \\
\hline Benzyl alkohol & 1042 & 3,18 & 0,574 \\
\hline 2-Methyl-2-hydroxy-2-pentanone & 940 & 2,85 & 0,570 \\
\hline Ethylene glycol & 1113 & 3,73 & 0,630 \\
\hline Propylene glycol & 1258 & 3,59 & 0,537 \\
\hline 2,2`oxydiethanol & 1118 & 3,74 & 0,629 \\
\hline 2,4-Dihydroxy-2-Methylpentane & 922 & 3,31 & 0,675 \\
\hline Glicerol & 1258 & 3,73 & 0,557 \\
\hline n-Hexane & 655 & 1,87 & 0,537 \\
\hline Gasoline & 750 & 1,90 & 0,476 \\
\hline Cyclohexane & 774 & 2,49 & 0,605 \\
\hline n-Octane & 703 & 2,11 & 0,564 \\
\hline Toluene & 862 & 2,69 & 0,587 \\
\hline Diesel oil & 830 & 2,73 & 0,618 \\
\hline Acetone & 790 & 2,33 & 0,554 \\
\hline 4-methyl-2-pentanone & 800 & 2,43 & 0,571 \\
\hline Cyclohexanone & 942 & 2,94 & 0,587 \\
\hline Nitrobenzene & 1200 & 3,80 & 0,595 \\
\hline 4-Nitrotoluene & 1160 & 3,86 & 0,626 \\
\hline Methyl acetale & 934 & 2,60 & 0,523 \\
\hline Ethyl benzoate & 1050 & 2,97 & 0,532 \\
\hline 2-Methoxy-2-methylbutane & 770 & 2,10 & 0,513 \\
\hline
\end{tabular}




\begin{tabular}{|l|c|c|c|}
\hline \multicolumn{1}{|c|}{ Substance } & $\mathbf{d}, \mathbf{~ k g} \cdot \mathbf{m}^{-3}$ & $\mathbf{A}_{\mathbf{m a x}} \mathbf{~} \mathbf{~ g} \cdot \mathbf{k g}^{-1}$ & $\mathbf{A v}, \mathbf{~ m}^{\mathbf{3}} \cdot \mathbf{m}^{-\mathbf{3}}$ \\
\hline Chloroform & 1480 & 2,77 & 0,352 \\
\hline 1,4-Dioxane & 1027 & 3,05 & 0,558 \\
\hline Acetic acid & 1055 & 2,71 & 0,483 \\
\hline 85\% Phosphoric acid & 1710 & 5,11 & 0,562 \\
\hline 30\% Sulphuric acid & 1,22 & 3,86 & 0,595 \\
\hline 25\% Ammonia & 770 & 3,40 & 0,830 \\
\hline 40\% Sodium hydroxide & 1420 & 2,71 & 0,359 \\
\hline Water & 997 & 3,19 & 0,602 \\
\hline
\end{tabular}

\section{Conclusion}

The non swimming sorbents most frequently used in rescue operations have sorptivity within the range of $0.5-1.2 \mathrm{~kg} \mathrm{~kg}^{-1}$. Therefore, due to its sorptivity the waste of rigid polyurethane foam may be a very good starting material for the generation of a high performance sorbent. The sorptivity of the sorbent is reduced in the presence of foam agent solutions. Apart from concentrated sulphuric acid, the reaction of rigid polyurethane foam with the investigated sorbates has not been ascertained. Thanks to the low bulk density the sorbent could be used as filling of sorption mats designated for sorbing oil-based materials from the water surface, however, this requires additional surface hydrophobization. Low bulk density would hinder the use of sorbent in wind conditions.

The research was carried out as part of the DOB-BIO6 / 06/11/2014 project financed by NCBiR "Mobile turbine rescue and firefighting system."

\section{References}

1. http://www.straz.gov.pl/panstwowa_straz_pozarna/interwencje_psp(access 07.05.2018)

2. Król B., Prochaska K., Chrzanowski Ł., Biodegradability of Firefighting Foams, Fire Technology, 48, pp. 173-181, (2012)

3. Bourgeois A., Bergendahl J., Rangwala A., Biodegradability of fluorinated fire-fighting foams in water, Chemosphere, 131, pp. 104-109, (2015)

4. Colville S., McCarron N., Environmental issues associated with defence use of aqueous film forming foam (AFFF), Environmental Stewardship, Environment, Heritage and Risk Branch, May (2003)

5. Rakowska J., Porycka B., Zagrodzka M., Ekologiczne kierunki zmian bazy surowcowej w koncentratach gaśniczych, Bezpieczeństwo i Technika Pożarnicza, 19, pp. 107-116, (2010)

6. Hamilton S., Larson D., Finger S., Poulton B., Vyas N., Hill E., Ecological effects of fire retardant chemicals and fire suppressant foams, "Northern Prairie Wildlife Research Center", Jamestown (1998)

7. Caracciolo A. B, Cardoni M., Pescatore T., Patrolecco L., Characteristics and environmental fate of the anionic surfactant sodium lauryl ether sulphate (SLES) used as the main component in foaming agents for mechanized tunneling, Environmental Pollution, 226, pp. 94-103, (2017) 
8. Lechuga M., Fernández-Serrano M., Jurado E., Núñez-Olea J., Rios F., Acute toxicity of anionic and non-ionic surfactants to aquatic organisms, Ecotoxicology and Environmental Safety, 125, pp. 1-8, (2016)

9. Teresa Garcia M., Kaczerewska O., Ribosa I., Brycki B., Materna P., Drgas M., Biodegradability and aquatic toxicity of quaternary ammonium-based gemini surfactants: Effect of the spacer on their ecological properties, Chemosphere, 154, pp. 155-160, (2016)

10. Garcia M.T., Campos E., Sanchez-Leal J., Ribosa I., Effect of the alkyl chain length on the anaerobic biodegradability and toxicity of quaternary ammonium based surfactant, Chemosphere, 38, pp. 3473-3483, (1999)

11. Gancarczyk D, Jakubiec J., Sobolewski M, Effect of Sorbent Type on Efficiency of Oil Pollution Removal from Road Surface, Zeszyty Naukowe SGSP, 61, pp. 53-63, (2017) 